\title{
Development Pattern and Means of Local Cultural Tourism Resources-Taking Pingxiang Spring Gong as an Example
}

\author{
Yeqin Peng \\ Academy of Arts of Pingxiang University, Pingxiang City. Jiangxi Province. China, 337055
}

Keywords: Pingxiang spring gong; local folk art; cultural tourism resources

\begin{abstract}
In order to broaden the cultural channels of Pingxiang spring gong culture and combine the local traditional culture and tourism resources, it can build local cultural and cultural brands. But it also promotes the development of local cultural tourism industry, which can effectively inherit and carry forward the excellent local culture, promote and expand cultural consumption, improve social and economic benefits. It is necessary that make the cultural resources older people left realize the real "live up"!
\end{abstract}

\section{Introduction}

Combined with the "marriage" model of local traditional culture and tourism resources, it can create traditional folk art brand with local characteristics, but also promote the development of local cultural tourism industry. This paper analyzes the development pattern and means of local folk cultural tourism resources taking the national intangible cultural heritage- "Pingxiang spring gong" as an example.

\section{Digital Museum (Intangible Cultural Heritage) Model}

The so-called digital museum, refers to the cultural relics containing the history, culture, science and technology and other aspects of information for the collection, display the main body [1]. The network or other information channels were to spread, publish and promote, it promote an entity meaning the museum. The establishment of Pingxiang spring gong digital museum model can promote its "left" heritage innovation. The museum can set up traditional museums, modern museums, works exhibition hall, heritage hall, art museum, folk museum, commodity trading, etc. For traditional skills, folk literature, music and dance, drama, folk rituals as the carrier, it creates a comprehensive intangible cultural heritage museum model.

Modern high-tech means, such as on-site 3D printing, laser projection imaging, historical scene restoration, interactive experience perception and other technical practices on the history of Pingxiang spring gong, excellent inheritors, props, classic traditional tracks and other new models. On the Pingxiang spring gong of the documentary, We chat public number synchronized introduction Pingxiang spring gong details and audition classic repertoire, the scene of Pingxiang spring gong free field teaching, to create lovely lively Pingxiang gong cartoon characters, adding electronic, light and other audio and video devices. With three-dimensional modern high-tech means, we can create a fun and relaxing the environment to visit. In addition, this can also set up the game experience area (design and Pingxiang spring gongs related music interactive game), animation experience area, VR experience area and so on [2].

\section{"Pingxiang Spring Gong" Cultural Theme Park Model}

"Pingxiang spring gong" cultural theme park model should be established from the Pingxiang spring gongs and elements of the park and the overall design closely linked together through the garden of this carrier, carrying protection, research and showing Pingxiang spring gong. This place shows tradition function of art. The main projects include Huangmei Opera Cultural Attractions, Huangmei Opera Cultural and Commercial District, Performing Arts Zone, Vocational Education 
District, Living Area and Huangmei Opera Culture and Leisure Resort. After the completion of the Huangmei Opera theme park, Huangmei Opera is the theme of cultural elements [3]. Set tourism viewing, knowledge appreciation, casual play in one. "Spring gong" cultural theme park can also learn from this model built in addition to tourism centers, leisure centers and ecological centers and other traditional basic tourism industry, but also include the information technology industry and creative industries consisting mainly of leading industries, the use of Digital production and network communication as the main features of the digital content industry, while the use of high-tech means to transform and enhance the traditional cultural industries, so as to achieve the development of non-creative cultural industries [4]. But also add to enhance the industry, including the interpretation of industry, exhibition industry, education base and real estate and so on. This will not only make tourism, construction, transportation, communications, services, transportation, catering, culture, education and a large number of industries such as the rapid development of Pingxiang economic and social development will be incalculable great effect!

The specific implementation can be combined with the animation, the construction of Pingxiang spring gong animation theme park; or with the local scenic spots, founded Pingxiang spring gong characteristics "non-left" scenic modules.

\section{The Creation of Real Performance Mode}

After a great success, a series of "Impression" as the theme of the real performance mode hot, such as "Impression Lijiang", "Impression West Lake", "Impression Dahongpao", "Impression Putuo" and so on [5]. The "Impression" series of a distinctive feature is the "original ecology" and the introduction of modern scientific and technological means to build large-scale environmental art lighting engineering and visual, smoke effect. Learn from the "impression" series of successful cases, the Pingxiang Chun gong of the traditional forms of expression of the new, breaking the limitations of the traditional stage, and true mountain true water natural landscape combination (such as martial arts mountain, Wufeng Mountain, etc.), founded with personalized attraction of the local characteristics of landscape culture feast [6]. At the same time it is not only the concept of stage, but the cultural concept of large industry, belonging to the art of culture, but also belong to the tourism culture. It is the intangible cultural heritage "activation" of an important form of expression.

Draw the film "old aunt", drama "old aunt" and Pingxiang fishing drum "old aunt" success stories, Pingxiang spring gong can also be the old aunt's advanced deeds as a material for the creation of works to "pass positive energy, as the baseline, carry forward the local excellent moral model [7]. The real performance of the "old aunt" story as the theme, through Pingxiang spring gong as the carrier, it can carry forward Gong old aunt valuable spiritual wealth and firm belief, but also Pingxiang spring gong in a new gesture in front of the audience a Pingxiang local folk art and promote the local excellent moral model of the "live" business card.

\section{Tourism Culture Product Model}

\section{The Development of "Pingxiang Spring Gong" Mobile Client}

At October 3 in 2015, the "CPC Central Committee on the prosperity and development of socialist literature and art views" mentioned, "vigorously develop the network of literature and art, and promote the traditional literature and the integration of innovative network literature." Today is the "Internet +" era, to be good at grasp the law of communication, to strengthen the construction of key literary and art sites, good use of microblogging. We chat with mobile client and other carriers, to promote outstanding works multi-channel transmission, multi-platform display, multi-terminal push. With the advent of the $4 \mathrm{G}$ network, people habitually use the hands of convenient electronic equipment to obtain all kinds of information, such as listening to music, e-books, electronic journals are very common [8]. But the public is currently to use the phone to enjoy the opera. Opera programs are still more fragmented form, we must explore a more systematic way to facilitate the public "see", "listen", "learn", "assessment", and even a platform that can trade. 
"Pingxiang spring gong" to a new attitude in front of the public, must be combined with the current new form, founder of "Pingxiang spring gong" song mobile phone network client, you can combine Pingxiang spring gong own characteristics set up different display columns such as: in addition to the latest update of the latest Pingxiang Spring gong cultural advice and the "latest information", in addition to the latest update Pingxiang spring gong cultural advice and " performance information, but also in the client show Pingxiang spring gong cultural tourism resources development of new models such as: digital museum model, cultural theme park model.

Pingxiang spring gong "Zanping City" is a description of Pingxiang's history, celebrity deeds, cultural relics, places of historic interest and scenic beauty, customs, tourist attractions and other aspects of the work, such as the work mentioned in the food, (such as the user to listen to the user's name, the user's name, the product, the traditional story processing package, divided into different parts of the "Pingxiang spring gong" song mobile phone network client, (such as the user to listen to To the stage of a cultural heritage part of the further click, but also get a deeper understanding of the content), this way can no doubt Pingxiang spring gong to create a local publicity Pingxiang local characteristics of the personalized "dynamic" business card.

\section{"Pingxiang Spring Gong" Theme Online Game}

To create a unique theme of the network game is to promote Pingxiang spring gong their own development of a new means. In China, the combination of opera and online games has been a successful example. Online drama is the first background of the opera as the background of the game, the game a large number of music drama is a lot of famous contemporary composer to complete, select one of the most exciting of the most Beautiful ingredients, made a re-arranger making, accompanied by the game screen and the player's process and preferences, and even used nearly 100 years of the twenties and thirties of the last century, singing, in order to make the traditional opera by more audience to understand and attention [9]. Guangdong Opera Theater and Jinshan Software Xishanju studio together to create "cross-yuan" Cantonese opera "decisive battle of heavenly government", about the "Anshi chaos" during the promotion of justice story. The Guangdong Cantonese Opera Theater in the Cantonese opera performance road to make a new attempt, but also Cantonese opera and online games "cross-border" cooperation in the first case. The introduction of these games have attracted a lot of love of opera game enthusiasts.

Taking Pingxiang spring gong as the background, learn from today's popular online game model to create personalized characters, the establishment of the level system, the game players, need to go through Pingxiang spring gong of learning, teaching division, out of the disc, the creation of their own theater or create their own schools mark, and ultimately to dominate the theater, and to achieve the restoration of Pingxiang spring gong art of the lofty status of the mission. One of the learning, teaching these links must require players to personally imitate a variety of genre singing, not only to get the game genre founder of recognition, but also to be confirmed by other players. If the level reaches a certain level, you can create your own performance groups and theaters, and even be able to create their own genre art.

To create such a network of games for people of different ages, especially through the promotion of this game spread, you can achieve more love to play the game, and never touched the local traditional culture "Pingxiang spring gong" young generation. We re-understanding and love it, in order to achieve a more innovative online platform to promote the model.

\section{"Pingxiang Spring Gong" for The Original Production of Creative Elements of Tourism Products}

On May 16 in 2016, the general office of the State Council issued a number of opinions on promoting the development of cultural and cultural products in cultural and cultural relics units. The "opinions" was used for the production of "Pingxiang spring gong" creative products indicate the direction, you can use the "Internet + Pingxiang spring gong" model, the development of Pingxiang regional characteristics of the spring gong cultural tourism products and souvenirs, such as the design of a Pingxiang spring gong creative cartoon characters, characters image design by adding Pingxiang spring gong The use of props in the performance (drums, drums, gongs, gong hammer, red ribbon, etc.), showing lifelike, amiable, lovely and vivid image, and its cartoon image printed on 
other tourist souvenirs. Gong cultural tourism products and services design level, extending the relevant industry chain, to promote the spring gong cultural and creative product development and creative design, tourism and other related industries cross-border integration, so whether the local or foreign tourists experienced a full of physical and mental significance. After the cultural tourism, but also in the relevant mobile APP online to buy the relevant souvenirs, it will home secondary spread, then will spread spring gong folk culture, and the development of cultural industries, and enhance the role of local cultures Pingxiang economic transformation and upgrading.

\section{Shooting "Pingxiang Spring Gong" Film Micro Works}

Film and television micro-works refers to the small film, suitable for multimedia and modern networks, mobile video, elevator advertising and other platforms on display, more entertaining, creative and promotional value. Because of its local characteristics, "Pingxiang spring gong" in the micro-film shooting can also be taken from the ground, the script's creative content can be reflected in many aspects, such as show Pingxiang spring gong of the historical development process and manifestations; show Pingxiang local folklore life; show the current Pingxiang city, the national economy and social development of the new situation; show Pingxiang people's mental outlook and the pursuit of value and so on. The use of its short shooting cycle, low cost, wide dissemination, life characteristics, can make people better understand the intangible cultural heritage of the relevant cultural information and its artistic value.

\section{Festival Mode}

\section{Held Pingxiang Spring Gong Culture and Arts Festival}

China Peking Opera Festival, China Yue Opera Festival, China Kunju Art Festival and other models, are in recent years in the party and the government attaches great importance to the protection of the outstanding traditional culture of the product. Pingxiang Spring Gong Culture and Arts Festival [10], the contents of which can include the selection and performance of outstanding repertoire; held Pingxiang spring gong art seminar; held Pingxiang spring gong art series lectures; organization Pingxiang spring gongs performer performances and performances, etc. It can show Pingxiang spring gong of the repertoire heritage, creative achievements and personnel training the latest platform.

\section{Create a New Media Visual Electronic Concert}

Through the "new"-"old" art of the new collision, the use of high-tech and traditional Pingxiang spring gong folk art form to create a three-dimensional all-round audio-visual feast. The concert combines the traditional folk art with modern music elements, and makes use of the dynamic "rhythm" of the music to make the audience feel the rhythm of the picture and the rhythm, from the visual use of landscape devices, video devices and other artistic device effect. And the audience has a certain exchange of interaction, the electronics, light and shadow, modern technology and traditional traditional art combination bold attempt, giving a new visual auditory sensory experience. Such as the 2007 Shanghai Electronic Arts Festival "new visual electronic concert" is the Chinese intangible cultural heritage Kunqu for the baseline to build a new media visual electronic concert, and made a very big response.

\section{Summary}

It is a new model for the organic integration of economic construction and intangible cultural heritage, which can effectively inherit and carry forward the excellent local culture, promote and promote the cultural development of the non-material cultural heritage in order to expand the channel of Pingxiang Chun gong. Expand cultural consumption, improve social and economic benefits, so that the cultural resources older people left realize the real "live up"! There is a long way to go. 


\section{Acknowledgement}

This work was supported by "Research on the intangible cultural heritage of Jiangxi Province Pingxiang spring gong investigation and music research" (Jiangxi Province soft science research project, project number: 20161BBA10026), the type of project: general project; Peng Yeqin as the first host.

\section{References}

[1] Destinations: cultural landscapes of tourism[M]. Routledge, 2013.

[2] Telfer D J, Sharpley R. Tourism and development in the developing world[M]. Routledge, 2015.

[3] Mowforth M, Munt I. Tourism and sustainability: Development, globalisation and new tourism in the third world[M]. Routledge, 2015.

[4] Place-based education in the global age: Local diversity[M]. Routledge, 2014.

[5] Tourism and development: concepts and issues[M]. Channel View Publications, 2014.

[6] Stephenson M L. Tourism, development and 'destination Dubai': Cultural dilemmas and future challenges[J]. Current Issues in Tourism, 2014, 17(8): 723-738.

[7] Benur A M, Bramwell B. Tourism product development and product diversification in destinations[J]. Tourism Management, 2015, 50: 213-224.

[8] Williams D R, Kaltenborn B P. The use and meaning of recreational cottages in Norway and the USA[J]. Leisure/tourism geographies: Practices and geographical knowledge, 2013, 3: 214.

[9] Spangenberg J H, Görg C, Truong D T, et al. Provision of ecosystem services is determined by human agency, not ecosystem functions. Four case studies[J]. International Journal of Biodiversity Science, Ecosystem Services \& Management, 2014, 10(1): 40-53.

[10] de Salvo P, Hernández Mogollón J M, Di Clemente E, et al. Territory, tourism and local products. The extra virgin oil's enhancement and promotion: a benchmarking Italy-Spain[J]. Tourism and Hospitality Management, 2013, 19(1.): 23-34. 